\title{
Serum Levels of Transforming Growth Factor Beta1 (TGF ß1) in Patients with Alopecia Areata
}

\author{
Asmaa M. El-Refaey ${ }^{\text {a }}$, Doaa M. El-Habak ${ }^{\mathrm{a}}$, Rana A. Khashaba ${ }^{\mathrm{b}}$, Reham Abd Al-mageed $^{\mathrm{a}}$
}

a Department of Dermatology, Venereology and Andrology, Faculty of Medicine, Benha University, Egypt. ${ }^{\mathrm{b}}$ Department of Clinical and Chemical Pathology, Faculty of Medicine, Benha University, Egypt.

Correspondence to: Reham Abd Al-mageed, Department of Dermatology, Venereology and Andrology, Faculty of Medicine, Benha University, Egypt

Email:

rehamfawzybenha@gmail.com

Received: 22 April, 2020

Accepted:23 June, 2020

\begin{abstract}
:
Background: Alopecia areata (AA) is a chronic inflammatory disease that involves the hair follicle. Transforming growth factor $\beta$ - is a multipurpose cytokine which plays a role in many cellular functions such as proliferation, differentiation, migration, apoptosis, cell adhesion and regulation of epithelial to mesenchymal transition. Aim; the aim of this work was to evaluate the serum levels of TGF- $\beta 1$ in patients with AA by ELISA and correlate its level with severity. Methods: This study included sixty clinically diagnosed patients with AA, their ages ranged from five to fivty years and twinty five apparently healthy subjects were served as control. All studied individuals were subjected to history taking and clinical assessment of lesions according to clinical severity into mild, moderate and severe. We investigated serum level of TGF- $\beta 1$ using Enzyme-linked immunosorbent assay. Results: there was a highly statistically significant difference was found between the mean serum TGF- $\beta 1$ level of cases vs. controls. TGF- $\beta 1$ level of severe AA patients was higher than moderate AA patients and moderate cases were higher than mild cases. The level of TGF- $\beta 1$ was higher in AA patients that had disease duration > one month than AA patients
\end{abstract} with disease duration $\leq$ one month. There were statistically significant differences of serum TGF$\beta 1$ as regard age, higher in patients $>10$ years old and nail pitting, higher in patients with nail pitting. Conclusion: High levels of TGF- $\beta 1$ are present in patients with AA and positively correlate with severity, which may indicate a causal role of TGF- $\beta 1$ in pathogenesis of AA.

Keywords: Alopecia Areata; Transforming Growth Factor Beta1; TGF $\beta 1$ 


\section{Introduction}

Alopecia areata (AA) is a chronic inflammatory non-scarring condition affecting the hair follicle (HF) that leads to hair loss ranging from small well defined patches to complete loss of all body hair (MacLean et al., 2013.( The main theory of AA pathogenesis is that it is an autoimmune phenomenon resulting from a disruption in HF (1).

Alopecia areata typically presents as smooth, sharply demarcated, round patches of hair loss without atrophy with "exclamation point hairs" observed on the periphery of the patches. Special designations of the disease include alopecia universalis (AU) (total body hair loss), alopecia totalis (AT) (total scalp hair loss), or alopecia in an ophiasis pattern (band-like hair loss on the temporal and occipital scalp).

Less common variants include the diffuse variant with widespread thinning of hair across the scalp or the reticular pattern with recurrent hair loss in one area and spontaneous hair regrowth (2).

Many therapies are available for the treatment of AA including topical, systemic, and injectable modalities. However, these treatment methods produce variable clinical outcomes and there are no currently available treatments that induce and sustain remission (3).

Other skin conditions that may be confused with AA include traction alopecia, temporal triangular alopecia, androgenic alopecia, trichotillomania, tinea capitis, secondary syphilis, pressure-related alopecia, aplasia cutis, chemotherapy-induced alopecia, telogen effluvium, and the many forms of cicatricial alopecia (2).

There is an association with autoimmune diseases, including vitiligo, diabetes, pernicious anaemia and thyroid disease, suggesting that AA itself is an autoimmune disease, although this is still unproven (4).

Several growth factors appear to control the development and the cycle of HF such as epidermal growth factor (EGF), transforming growth factor (TGF), keratinocyte growth factor (KGF), vascular endothelial growth factor (VEGF) (5).

Transforming growth factor $\beta$ (TGF- $\beta$ ) is a multipurpose cytokine, which plays a role in many cellular functions such as proliferation, differentiation, migration, apoptosis, cell adhesion and regulation of epithelial to mesenchymal transition (6). 
Actions of TGF- $\beta$ are largely context dependent. For instance, TGF- $\beta$ is growth inhibitory to epithelial cells and many tumor cell-lines while it stimulates the growth of mesenchymal cells. TGF- $\beta$ also activates fibroblast cells to a myofibroblastic phenotype (7).

Transforming growth factor- $\beta$ production from dermal papillae (DP) is enhanced by androgens, and growth inhibition of HF cells is induced by TGF- $\beta$, and the hair cycle progresses from the anagen phase to the catagen phase. TGF $\beta$ plays an important role in controlling hair growth cycle, mainly regulating the initiation and stop of catagen phase (8).

Transforming growth factor- $\beta$ signalling is essential for wound healing, including both non-specific scar formation and tissuespecific regeneration. The transforming growth factor- $\beta$ family forms a group of three isoforms, TGF- $\beta 1$, TGF- $\beta 2$, and TGF$\beta 3$, with their structure formed by interrelated dimeric polypeptide chains (9).

In mature $\mathrm{HF}$, TGF- $\beta 1$ messenger ribonucleic acid (mRNA) is expressed in the inner hair root sheath, TGF- $\beta 2$ mRNA is expressed at the end of the epithelium, while TGF- $\beta 3$ in the neighboring district of the outer root sheath (ORS). Studies have found that expression of TGF- $\beta 1$ in HF cells have relations with epidermal repair. These studies suggest that TGF- $\beta$ signal transduction not only controls the initiation of catagen phase, but also participates in many other physiological activities, which is an extremely complex process (10).

Transforming growth factor- $\beta 1$ has chemotactic activity on proangiogenic inflammatory cells, directing them to the site of new vessel formation. TGF- $\beta 1$ together with other compounds induces apoptosis of endothelial cells. The main factor inducing apoptosis TGF- $\beta 1$, which would be mainly responsible for the sudden onset of catagen in the mechanism of caspase cascade activation (11).

The aim of this work was to evaluate the serum levels of transforming growth factor$\beta 1$ in patients with alopecia areata.

\section{Patients and methods}

This case-control study included sixty clinically diagnosed patients with alopecia areata were selected from outpatient clinic of Dermatology Department, Benha University Hospital.

Written informed consent was taken before the start of the study, which is approved by Ethics Committee for Human Research of Benha faculty of medicine. 


\section{Exclusion criteria}

1. Patients suffering from skin diseases rather than $\mathrm{AA}$.

2. Patients with any types of alopecia rather than AA.

3. Patients suffering from any systemic diseases other than the skin disease.

4. Patients suffering from thyroid diseases, autoimmune diseases, infectious diseases and tumors.

Clinical assessment of AA lesions according to clinical severity which divided into: mild (three or less patches of alopecia with a widest diameter of $3 \mathrm{~cm}$ or less or the disease limited to the eyelashes and eyebrows), moderate (existence of more than 3 patches of alopecia or a patch greater than $3 \mathrm{~cm}$ at the widest diameter without AT or AU) and severe (AT or AU or ophiasis (which defined as Snake-shaped plaques extending to the scalp border or loss of hair in the shape of a wave at the circumference of the head) (12). Also the extent of scalp hair loss was determined according to the severity of alopecia SALT score (13).

Each patient was subjected to full history taking, complete general examination and local examination to exclude any differential diagnosis and determine any local condition contraindicating the patient from being included in the study .
Both patients and controls were subjected to determination of serum level of Transforming Growth Factor beta 1 using Enzyme-linked immunosorbent assay (ELISA) (Human TGF- $\beta 1$ ELISA Kit catalog No: CUS-10025) was use. The assay was performed in a blind fashion on coded samples by an investigator who was not informed of the subject's clinical status, after the collection of all samples had been completed .

\section{Statistical analysis :}

All data were collected, tabulated and statistically analyzed using SPSS 20.0 for windows (SPSS Inc., Chicago, IL, USA 2011). Quantitative data were expressed as the mean $\pm \mathrm{SD} \&$ (minimum-maximum), and qualitative data were expressed as absolute frequencies (number) \& relative frequencies (percentage). Continuous data were checked for normality by using Shapiro Walk test. Independent samples Student's t-test was used to compare between two groups of normally distributed variables while Mann Whitney $U$ test was used for non- normally distributed variables. Kruskall Wallius test was used to compare between more than two groups of nonnormally distributed variables. Percent of categorical variables were compared using Chi-square test. All tests were two sided. P- 
value $<0.05$ was considered statistically significant and $p$-value $\geq 0.05$ was considered statistically insignificant (NS).

\section{Results}

This is study conducted on 60 patients with AA. Alopecia areata patients were 38 males (63.3\%) and 22 females (36.7\%) with mean age was 27 years old with mean SD $(27 \pm 12)$ years. Twenty five healthy subjects served as control. There were 20 males (80\%) and 5 females (20\%). Their mean age was 30 years old with mean SD $(30 \pm 10)$. There were no statistically significant differences between patients and control groups as regard to age and sex with ( $\mathrm{p} \geq 0.05)$, Table (1)

Highly statistically significant difference was found between AA patients and controls as regards the mean value of TGF- $\beta 1$. The mean vaiue of TGF- $\beta 1$ in patients was (5.02 \pm 4.5$)$ and in controls was $(2.2 \pm 0.65)$ with $(\mathrm{P} \leq 0.0001)$, figure (1)

Level of TGF- $\beta 1$ was statistically significant higher in patient with AA that had disease duration > one month than AA patients with disease duration $\leq$ one month $(\mathrm{P}=0.026)$. The level of TGF- $\beta 1$ was statistically insignificant higher in patients with no history of previous treatment than in patients with history of previous treatment $(\mathrm{P}=0.5)$.
The level of TGF- $\beta$ lin patients with history of no response to previous treatment was insignificant higher than in patients with history of response to previous treatment $(\mathrm{P}=0.36)$. The level of TGF- $\beta 1$ in patients with history of disease recurrence was higher than levels in patients with no history of disease recurrence $(\mathrm{P}=0.86)$ Table (2)

The level of TGF- $\beta 1$ was statistically significant higher in patients with $\mathrm{AA}$ as regards age with $(\mathrm{P}=0.006)$ and nail pitting with $(\mathrm{P}<0.001)$.

Alopecia areata patients $\geq 10$ years old had TGF- $\beta 1$ higher than patients $\leq 10$ years old. The TGF- $\beta 1$ level in males was insignificant lower than females with $(\mathrm{P}>0.05)$. There were statistically insignificant difference in level of TGF- $\beta 1$ as regards family history, history of atopy and atopic dermatitis with $(\mathrm{P}>0.05)$, Table (3)

There were statistically significant differences in level of TGF- $\beta 1$ as regards severity of the disease with $(\mathrm{P}=0.0001)$. TGF- $\beta 1$ level of severe AA patients was higher than moderate AA patients and moderate cases were higher than mild cases, figure 2. 

Table (1): Demographic characteristics of AA patients and control.

\begin{tabular}{|c|c|c|c|c|}
\hline \multirow{2}{*}{ Iten } & \multicolumn{2}{|c|}{ Studied groups } & \multirow[b]{2}{*}{$\chi^{2}$} & \multirow[b]{2}{*}{$\mathbf{p}$} \\
\hline & $\begin{array}{l}\text { alopecia areata patients } \\
\qquad(n=60)\end{array}$ & $\begin{array}{l}\text { Control } \\
(n=25)\end{array}$ & & \\
\hline \multicolumn{5}{|c|}{ Age per years } \\
\hline Mean \pm SD & $27 \pm 12$ & $30 \pm 10$ & $\mathrm{MW}=1.2$ & $0.22(\mathrm{NS})$ \\
\hline Min-max & $5-55$ & $4-55$ & & \\
\hline \multicolumn{5}{|l|}{ Sex } \\
\hline Male & $38(63.3)$ & $20(80)$ & 2.3 & $0.13(\mathrm{NS})$ \\
\hline Female & $22(36.7)$ & $5(20)$ & & \\
\hline
\end{tabular}

$\chi^{2}$ Chi square test, MW= Mann Whitnney U test, $\mathrm{NS}=$ non-significant

Table (2): Comparison between AA patients TGF- $\beta 1$ levels as regards duration of disease, previous treatment, previous response and recurrence.

TGF-ß1 ng/ml

Items

\begin{tabular}{llll} 
No & $\%$ & Mean \pm SD & Min-max \\
\hline
\end{tabular}

MW p

\section{Disease duration}

$\leq$ one month

$30 \quad 50$

$4.2 \pm 3.9$

1-18

$2.2 \quad 0.026(\mathrm{~S})$

>one month

$30 \quad 50$

$6 \pm 5$

2-22

Previous treatment

yes

no

$\begin{array}{ll}24 & 40 \\ 36 & 60\end{array}$

$4.4 \pm 3.6$

$5.4 \pm 5$

$1-15$

0.67

$0.5(\mathrm{NS})$

Response previous treatment

Yes

No

$\begin{array}{ll}16 & 66.7 \\ 8 & 33.3\end{array}$

$3.4 \pm 1.3$

$6.4 \pm 5.6$

1.9- 6.46

0.92

0.36(NS)

1- 15

\section{Recurrence}

yes

22

36.7

$6.1 \pm 6$

1- 22

0.17

0.86(NS)

no

$4.3 \pm 3.2$

1.7- 17 
Benha medical journal vol. 37 , issue 3, 2020

Table (3): Comparison of family history and other dermatological diseases of AA patients as regards TGF- $\beta 1$ $(\mathrm{n}=60)$.

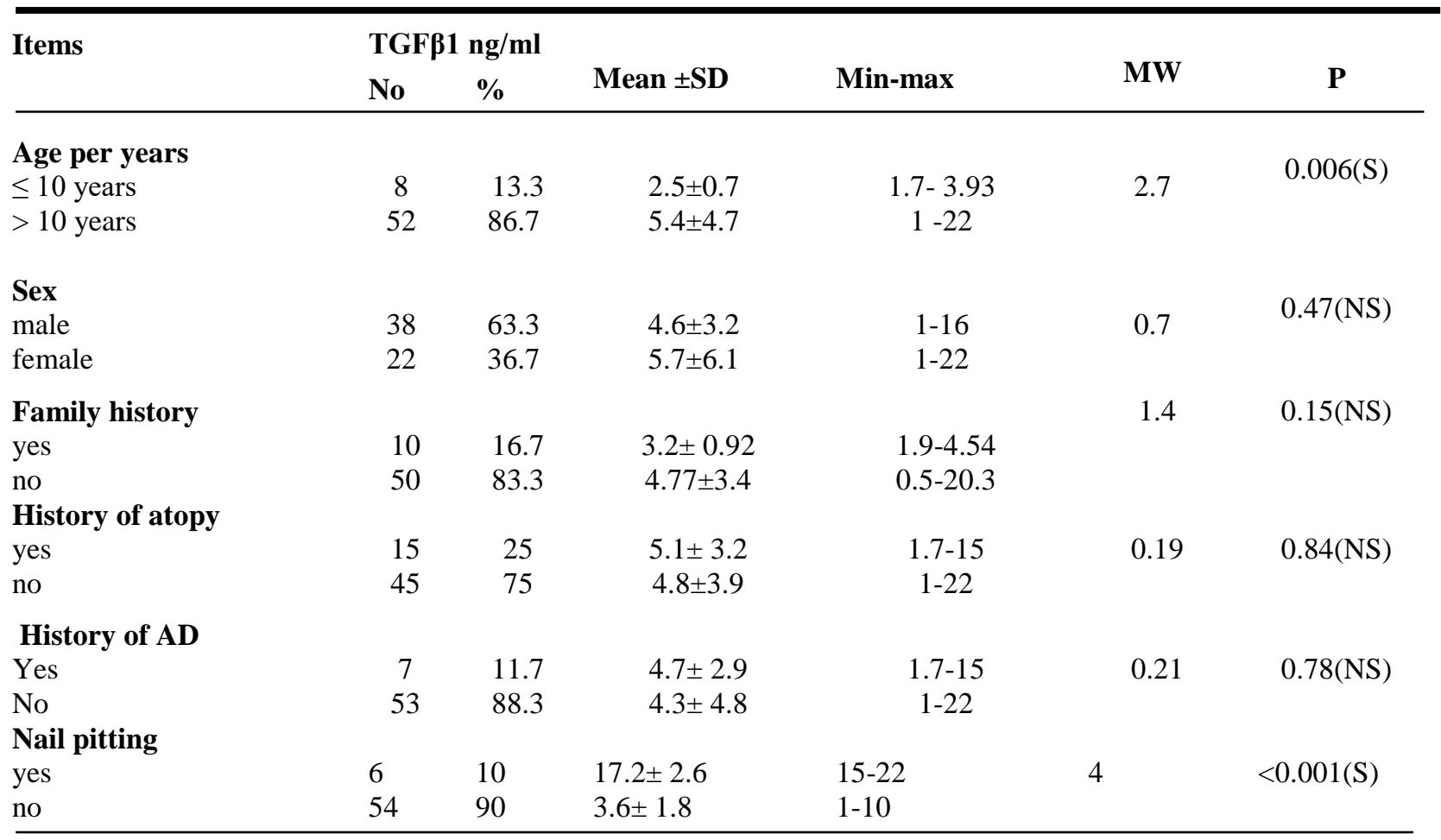

MW=Mann-Whitnney U test

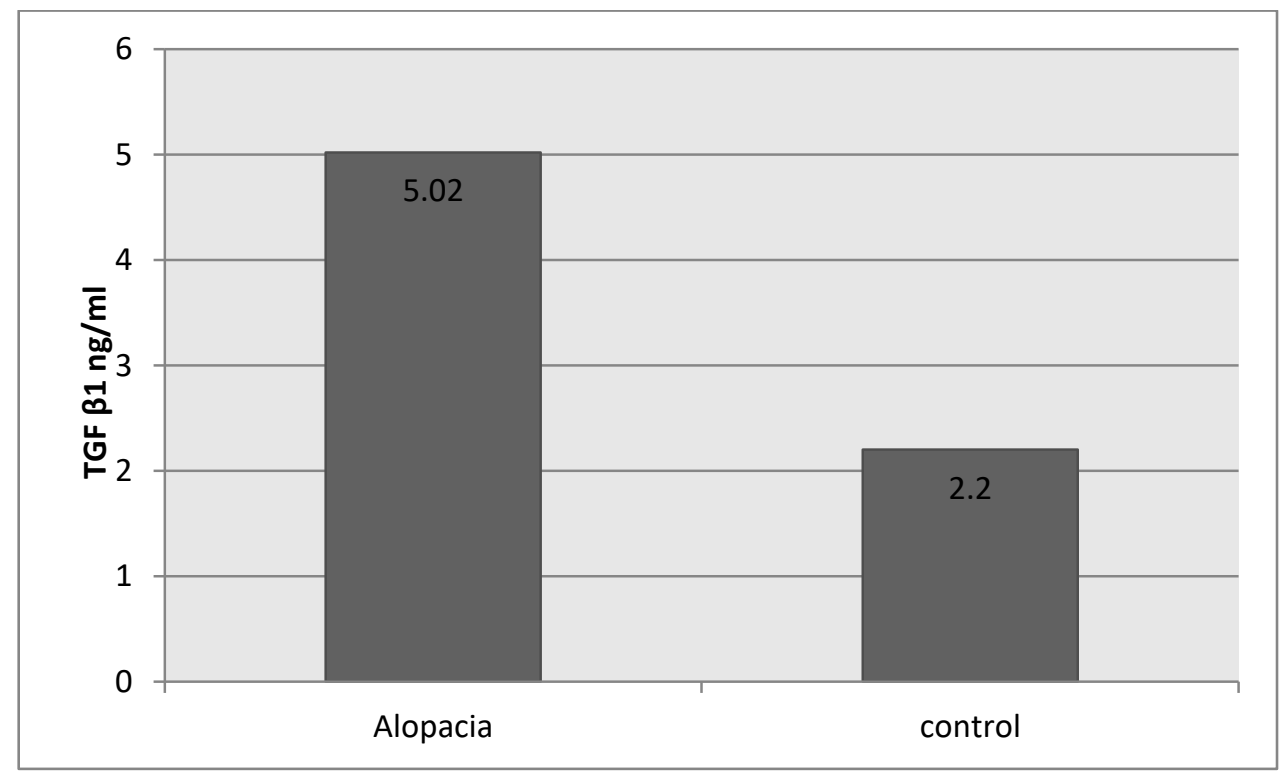

Fig. (1): Mean TGF- $\beta 1$ of AA patients and control group 


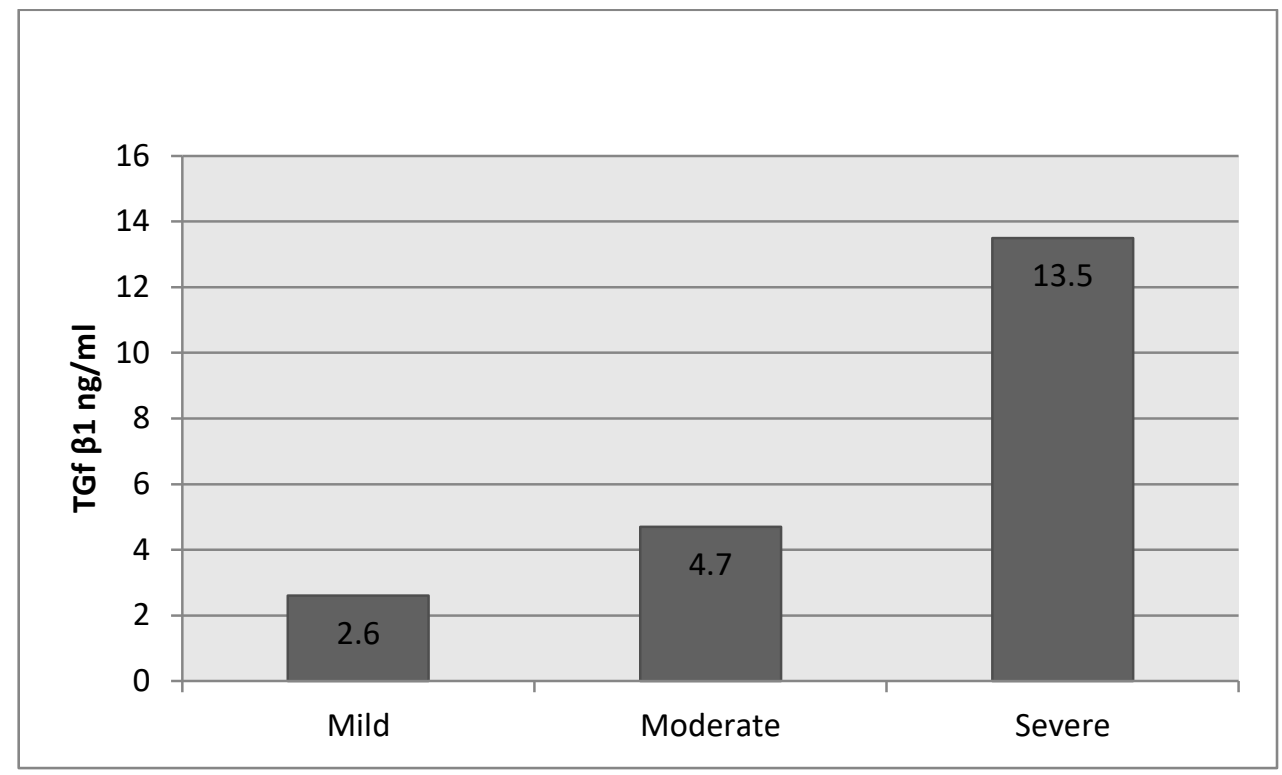

Fig. (2): Mean of TGF- $\beta 1 \mathrm{ng} / \mathrm{ml}$ of AA patients as regards severity level.

\section{Discussion}

The results of this study showed that the mean serum level of TGF- $\beta 1$ was statistically significant elevated in AA patients compared to controls $(\mathrm{p}<0.0001)$. The association of serum TGF- $\beta$ level and AA has been previously investigated with varying results.

Our results were parallel with Hong et al., (14) who suggested that TGF- $\beta 1$ has an important role in AA pathogenesis in inducing catagen hair and perifollicular fibrosis by modifying the extracellular matrix. Our results were parallel also with Loh et al., (15) study which showed statistically increase of serum TGF- $\beta$ level in AA patients in comparison to controls, $\mathrm{P}<$ $0 \cdot 05$.
In contrast to this study Tembrhe \& Sharma., (16) investigated Serum TGF- $\beta 1$ level in AA and found that the serum TGF$\beta 1$ levels were significantly decreased $(\mathrm{P}<$ 0.05) in patients with AA compared with controls. He attributed this result to the notion that the altered function of Tregs may lead to decreased serum TGF- $\beta 1$ levels in patients with active AA. The collapse of the anagen hair bulb IP due to altered function of Tregs or TGF- $\beta$ may play a crucial role in the pathogenesis of AA. Therefore, autoimmune diseases may be exacerbated in the absence of Tregs, or due to their malfunction

Also Katigiri et al., (17) study was designed to elucidate the immune status of AA and 
the similarity between AA and atopic dermatitis (AD) by analysis of in vivo levels of mRNA of Th1, Th2, and suppressive cytokines of peripheral blood mononuclear cells (PBMC). Using semi-quantitative RTPCR, the levels of cytokine mRNA were measured in freshly isolated PBMC of 47 patients with $\mathrm{AA}, 15$ patients with $\mathrm{AD}$, and 12 controls. The levels of IL-4, IFN- $\gamma$, and TGF- $\beta 1$ mRNA were lower in patients with AA $(\mathrm{P}<0.03)$ than those in controls due to down regulation of Th1 cytokines and up regulation of $\mathrm{Th} 2$ cytokines.

However in study by Chodorowska, et al., (18), who assessed the level of bFGF and TGF- $\beta 1$ in AA patients. He found that there were no significant difference in bFGF and TGF- $\beta 1$ levels between AA patients and normal controls $(\mathrm{P}>0.05)$. These differences in our study and the results of previous studies could be explained by the differences in inclusion and exclusion criteria, the differences in number of patients involved and to the different environmental factors which may affect TGF- $\beta 1$ level.

Regarding severity in the present study there was statistically significant difference between level of TGF- $\beta 1$ and severity of the disease $(\mathrm{P}=0.0001)$ as $\mathrm{TGF}-\beta 1$ level was higher in severe AA than moderate than mild types.
Loh et al., (15), studied TGF- $\beta 1$ and other cytokines in AA patients by using scalp biopsies from AA patients. Lesional TGF- $\beta$ was increase in patchy type, in AT and in AU. Moreover, the lesional level of TGF- $\beta$ mRNA was highest in AT/AU, and then in patchy type $(\mathrm{P}<0.05)$. Also he studied the cytokines in patients serum. According to clinical subtype of AA in patient group, serum TGF- $\beta$ was significantly increased in patchy type $(\mathrm{P}<0.05)$. These results support the involvement of Th17 cells in AA pathophysiology affecting severity.

In study by Katagiri et al., (17), the patients with AA were categorized into three groups as follows: mild AA with several small patches of hair loss (less than $3 \mathrm{~cm}$ in diameter), severe AA with more extensive hair loss than mild AA, and alopecia totalis. The mRNA levels of all cytokines (IFN- $\gamma$, IL-4, IL-10, TGF- $\beta 1$ ) were not statistically different between the combinations of any groups of AA (P>0.05). The levels of TGF$\beta 1 \mathrm{mRNA}$ also tended to be lower in group of AT than in the others.

In study by Tembhre \& Sharma., (16), The patients were classified into the following three groups: AA (patients $<10$ patches of hair loss), extensive AA (EAA; defined as hair loss involving $>40 \%$ of the scalp and/or more than 10 patches on the scalp, 
arms, legs or other sites in the past 3 months), and alopecia totalis or alopecia universalis. No significant difference was observed between the serum level of TGF$\beta 1$ when compared between the AA subgroups. However, the difference in median serum levels of TGF- $\beta 1(\mathrm{P}=0.059)$ were of borderline significance among the AA subgroups suggesting that the Tregs are severely compromised in the active phase of AA. Thus, breakdown of peripheral immune tolerance and enhanced T-cell-mediated immunity together may lead to the selective destruction of HFs in patients with AA.

\section{Conclusion}

High levels of TGF- $\beta 1$ are present in patients with AA and positively correlate with severity, which may indicate a causal role of TGF- $\beta 1$ in pathogenesis of AA.

\section{References}

1. Rajabi F, Drake LA, Senna MM, Rezaei N. Alopecia areata: a review of disease pathogenesis. Br J Dermatol. 2018;179(5):1033-48.

2. Darwin E, Hirt PA, Fertig R, Doliner B, Delcanto G, Jimenez JJ. Alopecia Areata: Review of Epidemiology, Clinical Features, Pathogenesis, and New Treatment Options. Int J Trichology. 2018;10(2):51-60.

3. Strazzulla LC, Wang EHC, Avila L, Sicco K Lo, Brinster N, Christiano AM, et al. Alopecia areata: an appraisal of new treatment approaches and overview of current therapies. J Am Acad Dermatol. 2018;78(1):15-24.

4. MacLean KJ, Tidman MJ. Alopecia areata: more than skin deep. Practitioner. 2013;257(1764):2932.

5. Kubanov AA, Gallyamova YA, Korableva OA, Kalinina PA. The Role of the VEGF, KGF, EGF, and TGF-B1Growth factors in the Pathogenesis of Telogen Effluvium in Women. Biomed Pharmacol J. 2017;10(1):191-8.

6. Chruścik A, Gopalan V, Lam AK. The clinical and biological roles of transforming growth factor beta in colon cancer stem cells: a systematic review. Eur J Cell Biol. 2018;97(1):15-22.

7. Chopra S, Kumar N, Rangarajan A, Kondaiah P. Context dependent non canonical WNT signaling mediates activation of fibroblasts by transforming growth factor- $\beta$. Exp Cell Res. 2015;334(2):24659.

8. Oshimori N, Fuchs E. Paracrine TGF- $\beta$ signaling counterbalances BMP-mediated repression in hair follicle stem cell activation. Cell Stem Cell. 2012;10(1):63-75.

9. Poniatowski ŁA, Wojdasiewicz P, Gasik R, Szukiewicz D. Transforming growth factor Beta family: insight into the role of growth factors in regulation of fracture healing biology and potential clinical applications. Mediators Inflamm. 2015;2015.

10. Liang X, Bhattacharya S, Bajaj G, Guha G, Wang Z, Jang $\mathrm{H}-\mathrm{S}$, et al. Delayed cutaneous wound healing and aberrant expression of hair follicle stem cell markers in mice selectively lacking Ctip2 in epidermis. PLoS One. 2012;7(2). 
11. Ferrari G, Terushkin V, Wolff MJ, Zhang X, Valacca C, Poggio P, et al. TGF- $\beta 1$ induces endothelial cell apoptosis by shifting VEGF activation of p38MAPK from the prosurvival p38 $\beta$ to proapoptotic p38 $\alpha$. Mol Cancer Res. 2012;10(5):605-14.

12. Kavak A, Baykal C, Özarmağan G, Akar U. HLA in alopecia areata. Int $\mathbf{J}$ Dermatol. 2000;39(8):589-92.

13. Olsen EA, Hordinsky MK, Price VH, Roberts JL, Shapiro J, Canfield D, et al. Alopecia areata investigational assessment guidelines-Part II. J Am Acad Dermatol. 2004;51(3):440-7.

14. Hong J-W, Lee C-Y, Ha S-M, Choi S-H, Kim $\mathrm{T}-\mathrm{H}$, Song K-H, et al. The contributory roles of Th17 lymphocyte and cytotoxic T lymphocyte at the hair bulge region as well as the hair bulb area in the chronic alopecia areata patients. Ann Dermatol. 2017;29(2):156-66.
15. Loh S, Moon H, Lew B, Sim W. Role of T helper 17 cells and $\mathrm{T}$ regulatory cells in alopecia areata: comparison of lesion and serum cytokine between controls and patients. J Eur Acad Dermatology Venereol. 2018;32(6):1028-33.

16. Tembhre MK, Sharma VK. T-helper and regulatory $\mathrm{T}$-cell cytokines in the peripheral blood of patients with active alopecia areata. $\mathrm{Br} \mathrm{J}$ Dermatol. 2013;169(3):543-8.

17. Katagiri $\mathrm{K}$, Arakawa $\mathrm{S}$, Hatano $\mathrm{Y}$. In vivo levels of IL-4, IL-10, TGF- $\beta 1$ and IFN- $\gamma$ mRNA of the peripheral blood mononuclear cells in patients with alopecia areata in comparison to those in patients with atopic dermatitis. Arch Dermatol Res. 2007;298(8):397-401.

18. Chodorowska G, Dabrowska-Czlonka M, Bartosinska J, Wawrzycki B, Jazienicka I. The level of bFGF and TGF-beta 1 in alopecia areata patients' sera and their role in angiogenesis. Postep Dermatologii i Alergol. 2007;24(3):116.

To cite this article: Asmaa M. El-Refaey ${ }^{\mathrm{a}}$, Doaa M. El-Habak, Rana A. Khashaba, Reham Abd Al-mageed. Serum Levels of Transforming Growth Factor Betal (TGF $\beta 1$ ) in Patients with Alopecia Areata. BMFJ 2020; 37(3):596-606, DOI: 10.21608/bmfj.2020.28466.1250 